\title{
Influence of the Cladding Structure in PMMA mPOFs Mechanical Properties for Strain Sensors Applications
}

Leal-Junior, Arnaldo G.; Frizera, Anselmo; Min, Rui; Pontes, Maria Jose; Fasano, Andrea; Woyessa, Getinet; Bang, Ole; Marques, Carlos

\section{Published in:}

IEEE Sensors Journal

Link to article, DOI:

10.1109/JSEN.2018.2842465

Publication date:

2018

Document Version

Peer reviewed version

Link back to DTU Orbit

Citation (APA):

Leal-Junior, A. G., Frizera, A., Min, R., Pontes, M. J., Fasano, A., Woyessa, G., Bang, O., \& Marques, C. (2018). Influence of the Cladding Structure in PMMA mPOFs Mechanical Properties for Strain Sensors Applications. IEEE Sensors Journal, 18(14), 5805-5811. https://doi.org/10.1109/JSEN.2018.2842465

\section{General rights}

Copyright and moral rights for the publications made accessible in the public portal are retained by the authors and/or other copyright owners and it is a condition of accessing publications that users recognise and abide by the legal requirements associated with these rights.

- Users may download and print one copy of any publication from the public portal for the purpose of private study or research.

- You may not further distribute the material or use it for any profit-making activity or commercial gain

- You may freely distribute the URL identifying the publication in the public portal 


\title{
Influence of the Cladding Structure in PMMA mPOFs Mechanical Properties for Strain Sensors Applications
}

\author{
Arnaldo G. Leal-Junior, Anselmo Frizera, Member, IEEE, Rui Min, Maria José Pontes, Andrea \\ Fasano, Getinet Woyessa, Ole Bang, and Carlos Marques
}

\begin{abstract}
This paper presents a dynamic mechanical analysis (DMA) of a microstructured polymer optical fiber (mPOF). The fiber material is polymethyl methacrylate (PMMA), which is widely available commercially. The DMA is made by means of sequential strain cycles produced with an oscillatory load with controlled frequency to obtain the variation of the Young's Modulus with respect to temperature, frequency and humidity for mPOFs with 2,3 and 5-ring hexagonal microstructured cladding. Results show that the 3 different cladding structures have similar Young's modulus on the stress-strain tests performed. Furthermore, the 3-ring structure presents the lowest Young's Modulus variation with temperature among the samples tested, whereas the 5-ring structure presents a Young's Modulus variation with frequency $25 \%$ lower than the 2 and 3-rings cladding structures. Regarding the humidity sensitivity, the 2ring structure presented a 30\% lower Young's Modulus variation for a $25 \%$ humidity increase. The results obtained provide guidelines for the cladding structure choice for strain or stress sensors applications when low cross-sensitivity with temperature, humidity and frequency is desired.
\end{abstract}

Index Terms-microstrutured polymer optical fiber, dynamic mechanical analysis, polymethyl methacrylate.

\section{INTRODUCTION}

$\mathrm{P}$ OLYMER optical fibers (POFs) present intrinsic advantages over the conventional silica optical fibers regarding its material features, including higher strain limits, lower

This research is financed by CAPES (88887.095626/2015-01), FAPES (72982608), CNPq (304192/2016-3 and 310310/2015-6). C. Marques acknowledges the financial support from FCT through the fellowship SFRH/BPD/109458/2015, program UID/EEA/50008/2013 by the National Funds through the Fundação para a Ciência e a Tecnologia / Ministério da Educação e Ciência, and the European Regional Development Fund under the PT2020 Partnership Agreement.

A. G. Leal-Junior, A. Frizera and M. J. Pontes are with the Graduate Program of Electrical Engineering of Federal University of Espírito Santo, Vitória, Brazil (e-mail:arnaldo.leal@aluno.ufes.br; frizera@ieee.org; mjpontes@ele.ufes.br).

R. Min is with ITEAM Research Institute, Universitat Politècnica de València, Valencia, Spain (e-mail: rumi@doctor.upv.es)

A. Fasano is with the Department of Mechanical Engineering, Technical University of Denmark, Denmark (e-mail: andreafasano.af@gmail.com).

G. Woyessa and O. Bang are with the Department of Photonics Engineering, Technical University of Denmark, Denmark (e-mail: gewoy@fotonik.dtu.dk; oban@fotonik.dtu.dk). O. Bang is also with SHUTE Sensing Solutions APS, Diplomvej 381, 2800 Kongens Lyngby, Denmark

C. Marques is with Instituto de Telecomunicações and Physics Department \& I3N, University of Aveiro, Portugal (carlos.marques@ua.pt).
Young's modulus, fracture toughness and biocompatibility [1]. For these reasons, POF sensors have been applied in the sensing of different parameters like strain [2], temperature [3], refractive index [4], angle [5], liquid level [6], relative humidity [7] and acceleration [8], antibodies [9]-[11], and glucose [12], [13].

Although there is considerable research towards obtaining POFs with different materials, such as Zeonex [14], TOPAS [15] and polycarbonate (PC) [16], to date, polymethyl methacrylate (PMMA) is the most employed material for POF manufacturing [17]. There are some reports of polymer optical fiber Bragg gratings (POFBGs) in multimode POFs [18]-[20]. However, POFBGs are usually inscribed in single-mode POFs, such as microstructured POFs (mPOFs) that present a pattern of holes through the fiber separated by a certain pitch [21]. If the ratio between holes and pitch is lower than 0.43, the fiber is endlessly single-moded [22].

The polymer is a viscoelastic material that does not present a constant response with stress or strain [23] and a creep or relaxation may be observed both in stress-strain cycles [24] and long term tests with strain cycles applied [25]. In addition, the Young's modulus variation of the PMMA mPOF was characterized in a frequency range of 1 to $2 \mathrm{kHz}$ in [26]. However, the effect of temperature and humidity on the Young's modulus variation of a PMMA mPOF also need to be characterized, since PMMA POFs present sensitivity to such parameters [27]. Furthermore, the Young's modulus variation with the temperature for bulk PMMA POFs and their relation with frequency variations are presented in [28]. However, the different POF microstructures can lead to different response to temperature, strain, humidity and frequency of the FBG, since it changes the stiffness of the POF, and since the air holes can act as thermal insulators. Moreover, the air-hole microstructure may also change the humidity response of the mPOF by means of increasing the contact area between the PMMA and the moisture if water penetrates into the holes. These effects can lead to a cross-sensitivity of temperature, humidity and movement frequency for strain or stress sensors.

In order to verify these assumptions, this paper presents a dynamic mechanical analysis (DMA) of mPOFs with different structures, where the DMA is comprised of sequential strain cycles by means of the application of an oscillatory load with controlled frequency. The DMA is applied to evaluate the 
Young's modulus variation with respect to temperature, humidity and frequency of PMMA mPOFs with hexagonal air-hole structures with 2, 3 and 5 rings. The analysis is made with respect to the general materials properties. Therefore, it helps in the development of the general POF sensor technology, instead of only a certain type of sensor, if the analysis was made with respect to a single sensor response.

\section{EXPERIMENTAL SETUP}

The PMMA mPOFs employed in this work have a length of $10 \mathrm{~mm}$ with a hexagonal air-hole pattern with 2, 3 and 5 rings of holes, where their hole diameter, pitch, fiber diameter, and solid material area are presented in Table I. In addition, Fig. 1 presents the cross-sectional view of each mPOF employed. The mPOFs were fabricated at Technical University of Denmark (DTU) in two steps: first a PMMA rod is drilled with a predefined hole diameter and pitch, which is extruded to form a rod with lower diameter. Then, in the second step, the rod is sleeved with PMMA tubes, resulting in a new preform that is extruded again. Therefore, the inner part of the fiber is extruded two times, whereas the outer part is extruded only one time. In addition, the inner and outer part of the mPOFs were drawn in different times. Thus, it is possible that differences in the fabrication process, such as applied stress in the drawing or preform annealing resulted in this slight color difference between the inner and outer part of the fiber. Since the fiber is made with the same material (PMMA), we do not expect that such slight differences will lead to large differences in the material properties.

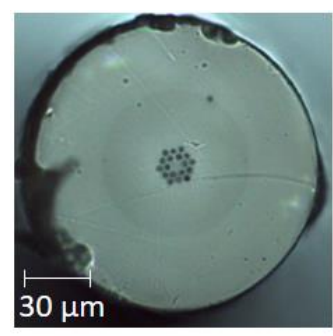

(a)

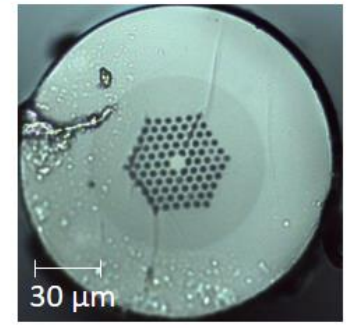

(c)

Fig. 1. Cross-sectional view of the mPOFs employed on the DMA. (a) 2-rings $\mathrm{mPOF}$, (b) 3-rings $\mathrm{mPOF}$ and (c) 5- rings $\mathrm{mPOF}$.

TABLE I

GEOMETRICAL PARAMETERS OF THE PMMA MPOFS

\begin{tabular}{cccc}
\hline \hline $\begin{array}{c}\text { Cladding } \\
\text { Structure }\end{array}$ & $\begin{array}{c}\text { Hole } \\
\text { diameter/pitch } \\
(\mu \mathrm{m})\end{array}$ & $\begin{array}{c}\text { POF diameter } \\
(\mu \mathrm{m})\end{array}$ & $\begin{array}{c}\text { Solid Material } \\
\text { Area }\left(\mathrm{mm}^{2}\right)\end{array}$ \\
\hline 2 ring hexagonal & $1.70 / 3.95$ & $138 \pm 13$ & $1.49 \times 10^{-2}$ \\
3 ring hexagonal & $1.90 / 4.60$ & $139 \pm 11$ & $1.51 \times 10^{-2}$ \\
5 ring hexagonal & $1.70 / 3.95$ & $140 \pm 15$ & $1.52 \times 10^{-2}$
\end{tabular}

The cleaving of mPOFs is an important process prior to its connectorization, the cleaving parameters, such as temperature, speed, and angle, can influence the quality of the $\mathrm{mPOF}$ end facet [29]. For this reason, the employed mPOFs are cleaved with a razor blade perpendicular to the fiber at about $50^{\circ} \mathrm{C}$. In some applications of POFBG sensors the POF need to be annealed, since the annealing can reduce the sensor hysteresis and provide higher sensitivity for certain type of sensors [14], [30], [31], all the samples were pre-annealed for 24 hours at $80^{\circ} \mathrm{C}$.

After the preparation of the samples, the mPOFs are positioned on the dynamic mechanical analyzer DMA 8000 (Perkin Helmer, USA) presented in Fig. 2. The length of the fiber samples is about $10 \mathrm{~mm}$, whereas each clamp has $3 \mathrm{~mm}$ length (see Fig. 2). Therefore, only $4 \mathrm{~mm}$ of the fiber will be under test. Thus, the longitudinal uniformity of the fiber will present lower influence in the tests results, since such small portion of the fiber is under stress, temperature, frequency or humidity variations. For this reason, we are not considering the longitudinal uniformity of the fiber in the performed tests.

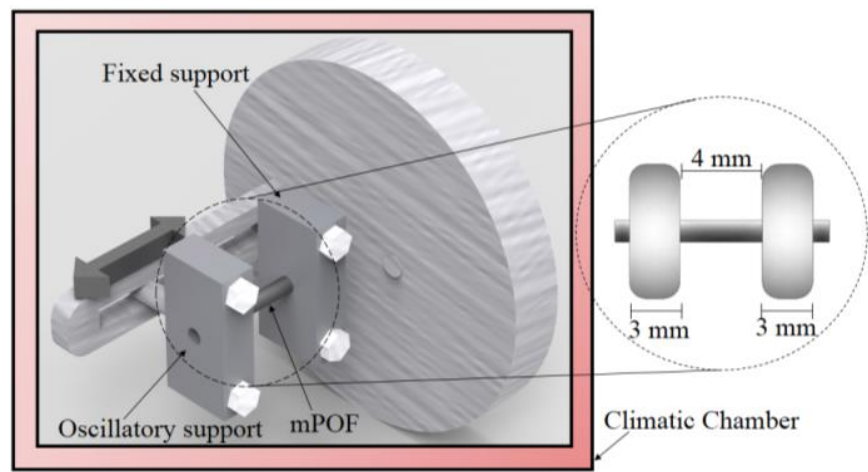

Fig. 2. mPOF samples fixation and geometrical parameters for the DMA tests.

The DMA is performed by applying an oscillatory load with controlled frequency and amplitude in the mPOF sample positioned as shown in Fig. 2. One end of the fiber is fixed in the oscillatory support, which applies the load on the sample, whereas the other end is fixed without movement. In addition, a load cell is positioned in within the fixed support to measure the stress in the sample and a linear variable differential transformer (LVDT) sensor is positioned in the oscillatory support to measure the fiber strain. In these tests, the strain is below $1 \%$ in order to keep the sample stress within the elastic region, where the well-known Hooke's law can be applied to obtain the fiber Young's modulus. Thus, the Young's modulus is estimated by the ration between stress and strain in the fiber material. Additionally, the analyzer contains a climatic chamber for humidity and temperature control, and the control of the strain and frequency is made by means of the displacement and velocity control of the movable support illustrated in Fig. 2. First, a stress-strain test was made on the mPOFs with constant temperature of $25^{\circ} \mathrm{C}$ and humidity of $78 \%$ to evaluate the Young's modulus of each fiber. Then, a temperature scan was made from $25^{\circ} \mathrm{C}$ (room temperature) to about $100^{\circ} \mathrm{C}$, which is a temperature below the PMMA glass transition temperature (Tg) [15]. Furthermore, tests with humidity variation from about $75 \%$ to $95 \%$ are made with the mPOFs to evaluate their humidity sensitivity. The frequency 
of the strain cycles is also varied to evaluate the Young's modulus dependency on the frequency for frequencies lower than $10 \mathrm{~Hz}$. Then, tests with the variation of both humidity and temperature are made to evaluate if the mPOFs presents a cross-sensitivity between these parameters.

\section{RESULTS AND DISCUSSION}

The goal of the stress-strain cycles is to obtain the Young's modulus of each sample. For this reason, the cycles are made for strains below $0.25 \%$, which is the region recommended for the evaluation of the Young's modulus in polymers by the standard ISO 527-1:2012, where the Young's modulus is obtained by the slope of the linear regression at each stressstrain curve. Figure 3 (a) presents the Young's modulus obtained for each cladding structure, where the mean and standard deviation were obtained from 3 tests with 3 different $10 \mathrm{~mm}$ lengths of the mPOF with that cladding structure. It is worth to mention that all cycles were made with a controlled temperature of $25^{\circ} \mathrm{C}$ and constant relative humidity of $78 \%$. In order to show the effect of the temperature on the stress cycle, Fig. 3(b) shows the stress-strain curve for the 5-ring mPOF with 3 different temperatures, namely $25^{\circ}, 70^{\circ} \mathrm{C}$ and $95^{\circ} \mathrm{C}$ in a constant humidity environment of $78 \%$. In addition, the effect of the relative humidity on the stress cycle is presented in Fig. 3(c), where the 5-ring mPOF is submitted to 3 different relative humidity conditions $(25 \%, 78 \%$ and $95 \%)$ in a constant temperature of $25^{\circ} \mathrm{C}$.

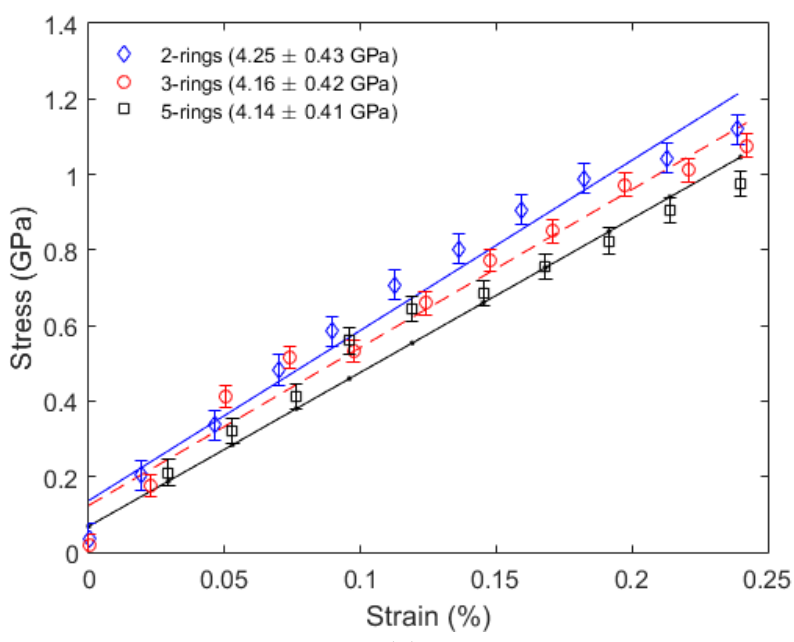

(a)

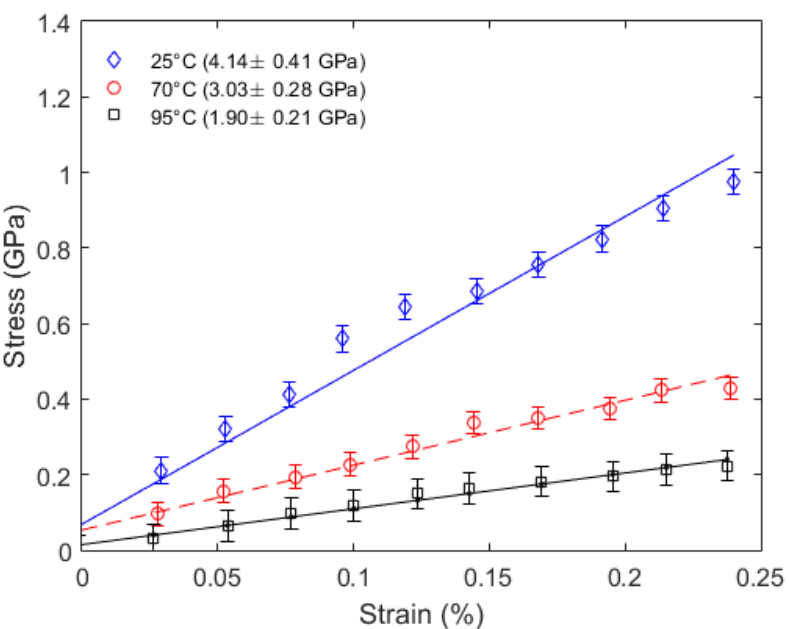

(b)

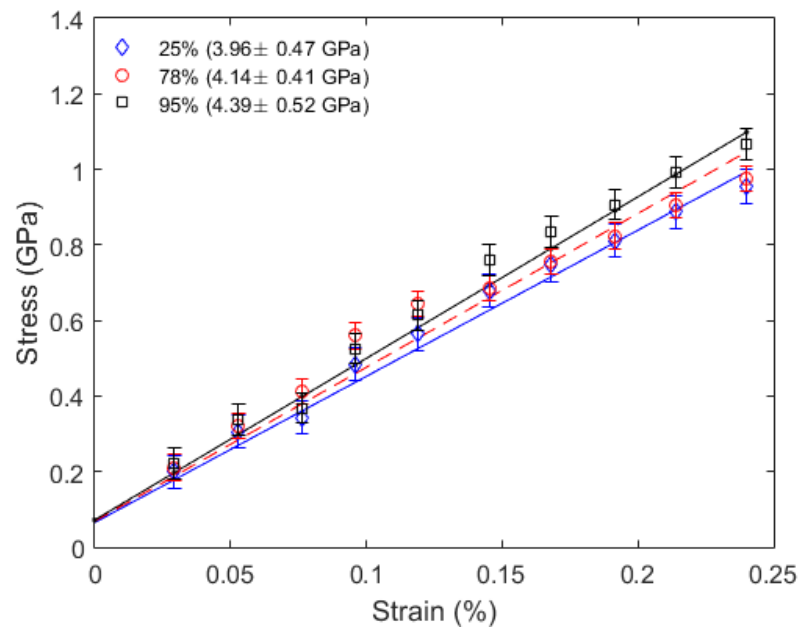

(c)

Fig. 3. (a) Stress-strain cycles and Young's Modulus for the 2-ring (blue), 3ring (red), and 5 ring (black) $\mathrm{mPOF}$. (b) Stress-strain curves for the 5-ring $\mathrm{mPOF}$ at $25^{\circ} \mathrm{C}$ (blue), $70^{\circ} \mathrm{C}$ (red) and $95^{\circ} \mathrm{C}$ (black). (c) Stress-strain curves for the 5-ring mPOF at humidity of 25\% (blue), $78 \%$ (red) and 95\% (black).

The results show that there could be a slight dependency of the Young's Modulus on the cladding structure, which can be due to the reduction of the cross-sectional area of solid material presented in Table I. However, the difference between the Young's Modulus of the $3 \mathrm{mPOF}$ types is small, indicating that such difference is not significant. In addition, the standard deviation of each mPOF measurement is about $0.4 \mathrm{GPa}$, which is lower than the difference between the maximum Young's modulus, obtained for the 2-rings mPOF, and the minimum (for the 5-rings $\mathrm{mPOF}$ ), where such difference is about $0.11 \mathrm{GPa}$. Regarding the temperature effect, there is a variation of the stress-strain slope due to the temperature that leads to a reduction of the fiber Young's Modulus. Similar behavior is found with the relative humidity variation. However, the temperature leads to higher variation of the modulus than the relative humidity.

In order to show the temperature effect in all cladding structures presented, temperature tests were made following the ASTM D5418 standard with each mPOF and the Young's modulus variation is presented in Fig. 4, where it can be seen that the 5-ring $\mathrm{mPOF}$ presented the higher variation of its Young's modulus. 


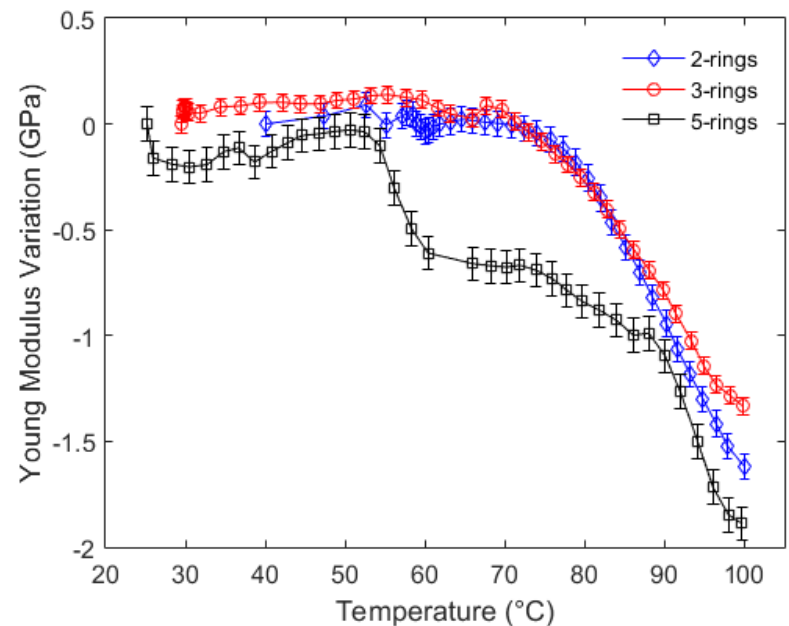

Fig. 4. Young's Modulus versus temperature for the 2-ring (blue), 3-ring (red), and 5 ring (black) mPOF.

The test is made with a temperature increase in steps of $2^{\circ} \mathrm{C}$ with a soak time of 1 minute as recommended by ASTM D5418 standard for temperature sweep in DMA. The strain cycle is made within about 1 second (frequency of $1 \mathrm{~Hz}$ ) and the interval between the strain cycles is about 1 minute (soak time of 1 minute) when the temperature is increased by $2{ }^{\circ} \mathrm{C}$ and another strain cycle is made. As the temperature is higher than $80^{\circ} \mathrm{C}$ and approaches the $\mathrm{Tg}$, the 5-rings fiber presented a sharp decrease of its Young's Modulus, which can be related to the higher difference in temperature along the fiber crosssection that such microstructure presents. In contrast, the 2rings fiber presents a lower temperature gradient along the mPOF cross-section, which leads to a linear decrease of the Young's Modulus as the temperature approaches the PMMA $\mathrm{T}_{\mathrm{g}}$. In addition, the Young's Modulus of the 2 and 3-rings $\mathrm{mPOFs}$ presented a lower variation in temperatures lower than $80^{\circ} \mathrm{C}$ than the ones of the 5-ring PMMA fiber. However, it should be noted that the 3-ring structure shows the lowest variation, which may also be related to the lower hole-to-pitch ratio than 2-ring and 5-ring fibers, since the fiber with lower hole-to-pitch ratio presented the lower temperature variation due to the highest homogeneity of the fiber cross-section. A lower Young's Modulus variation with the temperature may be preferred if a temperature sensor with lower strain crosssensitivity is desired.

The Young's Modulus variation for the oscillatory load frequency variation from $0.01 \mathrm{~Hz}$ to $10.00 \mathrm{~Hz}$ is presented in Fig. 5. Such frequency variation is within the range of some applications of joint angle measurements [5].

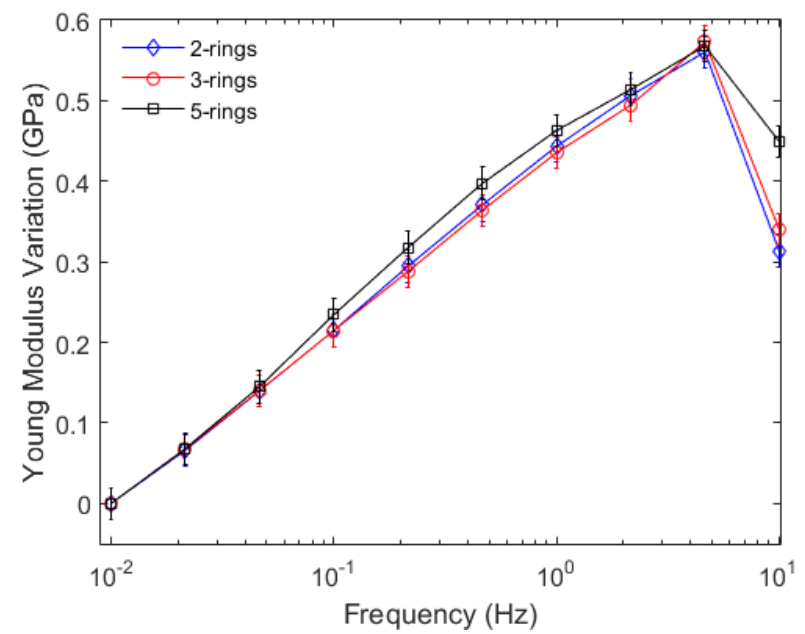

Fig. 5. Young's Modulus versus frequency for the 2-ring (blue), 3-ring (red), and 5 ring (black) mPOF.

Regarding Fig. 5, the variation of the Young's Modulus presented an upward trend for all the samples until the frequency of $5 \mathrm{~Hz}$ is reached. After that, the variation of the Young's Modulus starts to decrease and the lowest decrease among the samples tested is the one of the 5-ring structure, which was $25 \%$ lower than for the 2-rings structure. Such lower decrease indicates a lower cross-sensitivity with the movement velocity for the 5-ring cladding structure that can be an advantage for angle sensors for flexion/extension cycles [18] and accelerometers [9]. The lower decrease may be related to a natural damping that the air hole structure promotes on the fiber that will be higher on the 5-ring structure than on the structures with lower number of rings.

Finally, tests with relative humidity variation are made to evaluate the effect of the microstructure on the fiber humidity sensitivity. Figure 6 shows the variation of the Young's Modulus for a humidity variation from $75 \%$ to $95 \%$, where the lower bound of the test is due to the room environmental conditions. Both upper and lower bounds are left to stabilize for about 30 minutes each.

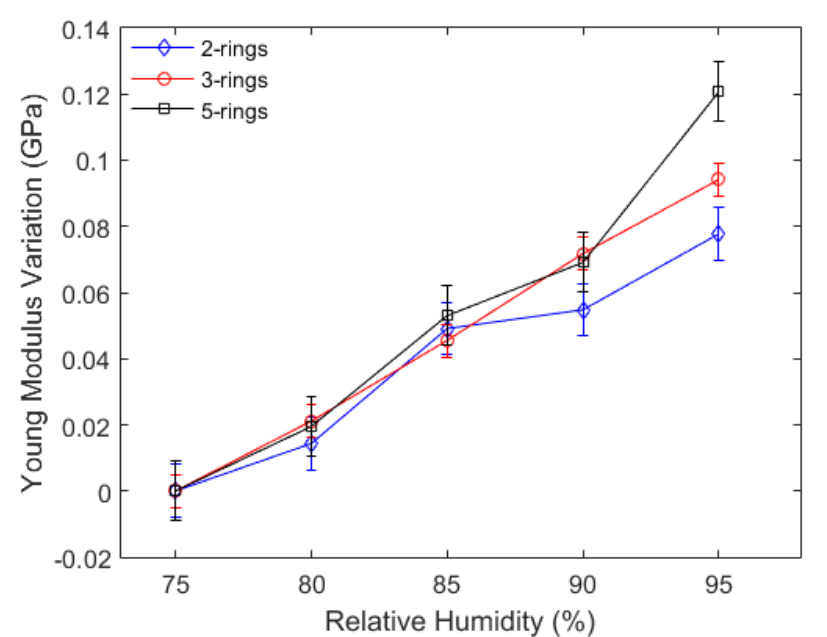

Fig. 6. Young's Modulus versus relative humidity for the 2-ring (blue), 3-ring (red), and 5-ring (black) mPOF.

Results show that the 5-rings cladding structure presents higher sensitivity than the others tested, whereas the lower 
sensitivity was obtained in the 2-rings structure. Since the 5rings structure presents more air holes, there will be more contact area between the PMMA and the humid air, which leads to a higher and faster water absorption of the 5-rings $\mathrm{mPOF}$. For this reason, if it is desired a lower humidity crosssensitivity, the 2-rings structure will present better performance than 3 and 5-rings cladding structures with a Young's Modulus variation of about 30\% lower than the one of the 5-rings mPOF.

In order to present a broader comparison between the cladding structures, tests with simultaneous variation of the temperature and relative humidity are presented. In these tests, the strain cycles are made at $25^{\circ} \mathrm{C}, 70^{\circ} \mathrm{C}$ and $95^{\circ} \mathrm{C}$ with a relative humidity of $25 \%$. Then, cycles are repeated with the same temperatures, but with the relative humidity at about $75 \%$ and, finally, at a relative humidity of $95 \%$ for each cladding structure analyzed. The results obtained for the 2rings, 3-rings and 5-rings mPOFs are presented in Fig. 7(a), (b) and (c), respectively.

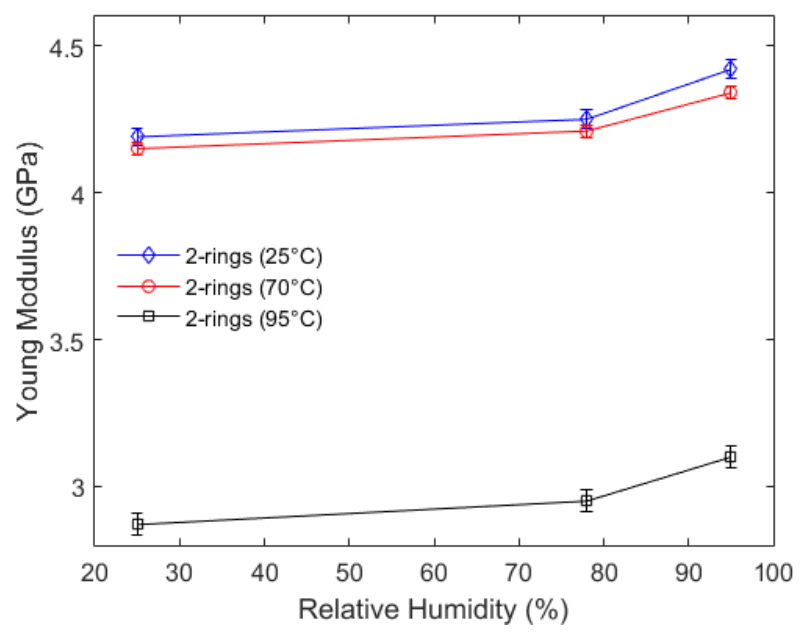

(a)

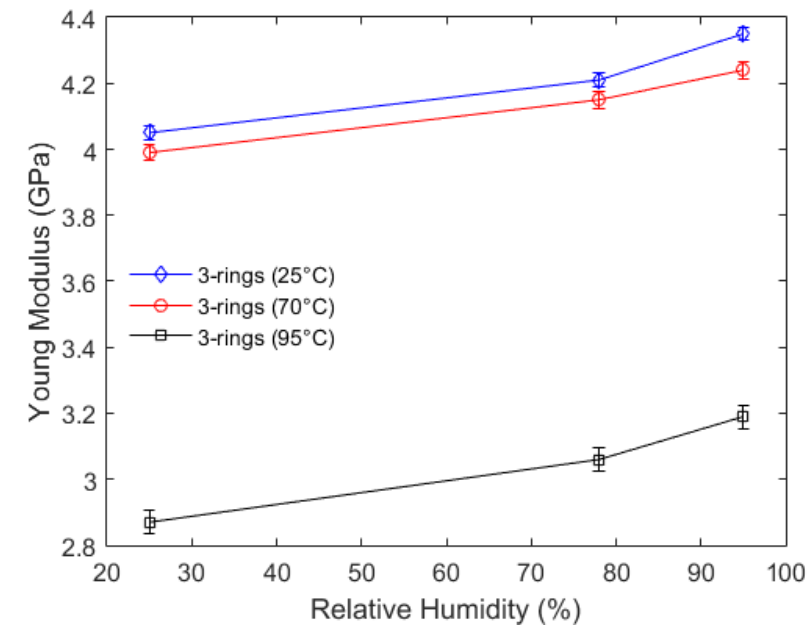

(b)

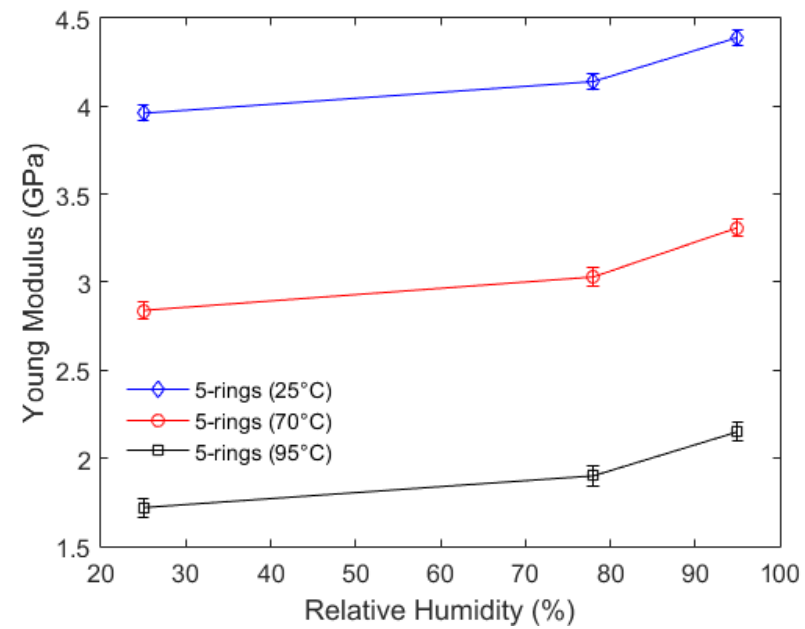

(c)

Fig. 7. Young's Modulus versus relative humidity in different temperature for (a) 2-ring, (b) 3-ring, and (c) 5-ring $\mathrm{mPOF}$.

Regarding to Fig. 7, the offset of the curves is due to the temperature variation. For the case of 2-rings and 3-rings mPOFs there is only a slight variation of the Young's Modulus in temperatures lower than $70^{\circ} \mathrm{C}$. For this reason, the blue and red curves of Fig. 7(a) and (b) are close to each other, whereas the 5-ring $\mathrm{mPOF}$ presented similar offset in all temperatures tested due its higher Young's Modulus variation with temperature that is demonstrated in both Fig. 4 and Fig. 7(c). In addition, the highest variation of the modulus with respect to the relative humidity was obtained in the 5-ring cladding structure in all temperatures tested (see Table II). In order to verify if there is a cross-sensitivity between relative humidity and temperature on the mPOF Young's Modulus, Table II presents the modulus variation for the cladding structures tested in each temperature.

The Young's Modulus presented almost constant variation in all temperatures tested for each of the three cladding structures analyzed. The highest standard deviation of the Young's Modulus when comparing the same relative humidity level at different temperatures was obtained in 3-rings mPOF. However, the standard deviation remains lower than $0.03 \mathrm{GPa}$, which can indicate that the temperature does not lead to high variations on the slope curve of the Young's Modulus with respect to the humidity variation.

TABLE II

YOUNG'S MODULUS VARIATION IN EACH HUMIDITY AND TEMPERATURE TESTS FOR THE PMMA MPOFS

\begin{tabular}{cccc}
\hline & TESTS FOR THE PMMA MPOFs & \\
\hline \hline Cladding & Young's & Young's & Young's \\
Structure & $\begin{array}{c}\text { Modulus } \\
\text { variation at } \\
25^{\circ} \mathrm{C}(\mathrm{GPa})\end{array}$ & $\begin{array}{c}\text { Modulus } \\
\text { variation at } \\
70^{\circ} \mathrm{C}(\mathrm{GPa})\end{array}$ & $\begin{array}{c}\text { Modulus } \\
\text { variation at } \\
95^{\circ} \mathrm{C}(\mathrm{GPa})\end{array}$ \\
\hline 2 ring hexagonal & $0.23 \pm 0.03$ & $0.19 \pm 0.02$ & $0.22 \pm 0.04$ \\
3 ring hexagonal & $0.28 \pm 0.02$ & $0.25 \pm 0.02$ & $0.31 \pm 0.03$ \\
5 ring hexagonal & $0.43 \pm 0.05$ & $0.47 \pm 0.05$ & $0.45 \pm 0.06$
\end{tabular}

\section{CONCLUSIONS}

This paper presented the comparison between different mPOFs Young's modulus variation with respect to temperature, frequency and humidity. The employed PMMA mPOFs present a hexagonal microstructure with 2, 3 and 5- 
rings and are positioned on a DMA for the tests. A stressstrain test was made on each fiber and shows that there is not a significant variation of the Young's Modulus for different cladding structures and temperatures tests show that the 3rings $\mathrm{mPOF}$ presents the lower variation of its Young Modulus with this parameter. In contrast, 5-ring structure presents a frequency dependency $25 \%$ lower than the other tested mPOFs, providing advantages on accelerometers and oscillatory movement assessment applications. Finally, the humidity tests show that the 2-ring structure presents a sensitivity $30 \%$ lower than the others mPOFs. The humidity tests were repeated in different temperature conditions and there was not a considerable variation of the mPOF sensitivity to relative humidity when the temperature is changed. Such tradeoff points towards the possibility of optimization of the cladding structure of an mPOF for each sensor application, which will be investigated in future works.

\section{REFERENCES}

[1] K. Peters, "Polymer optical fiber sensors-a review," Smart Mater. Struct., vol. 20, no. 1, p. 13002, 2011.

[2] A. Pospori, C. A. F. Marques, O. Bang, and D. J. Webb, "Polymer optical fiber Bragg grating inscription with a single UV laser pulse," Opt. Express, vol. 25, no. 8, pp. 9028-9038, 2017.

[3] W. Zhang, D. J. Webb, and G.-D. Peng, "Enhancing the sensitivity of poly(methyl methacrylate) based optical fiber Bragg grating temperature sensors," Opt. Lett., vol. 40, no. 17, p. 4046, Sep. 2015.

[4] A. R. Prado et al., "Polymethyl methacrylate (PMMA) recycling for the production of optical fiber sensor systems," Opt. Express, vol. 25, no. 24, p. 30051, Nov. 2017.

[5] A. G. Leal-Junior, A. Frizera, and M. J. Pontes, "Dynamic Compensation Technique for POF Curvature Sensors," J. Light. Technol., vol. 8724, no. c, pp. 1-1, 2017.

[6] C. A. F. Marques, G.-D. Peng, and D. J. Webb, "Highly sensitive liquid level monitoring system utilizing polymer fiber Bragg gratings," Opt. Express, vol. 23, no. 5, pp. 6058-6072, 2015.

[7] G. Rajan, Y. M. Noor, B. Liu, E. Ambikairaja, D. J. Webb, and G. D. Peng, "A fast response intrinsic humidity sensor based on an etched singlemode polymer fiber Bragg grating," Sensors Actuators, A Phys., vol. 203, pp. 107-111, 2013.

[8] A. Stefani, S. Andresen, W. Yuan, N. Herholdt-Rasmussen, and O. Bang, "High sensitivity polymer optical fiber-bragg-grating-based accelerometer," IEEE Photonics Technol. Lett., vol. 24, no. 9, pp. 763-765, 2012.

[9] G. Emiliyanov, P. E. Høiby, L. H. Pedersen, and O. Bang, "Selective serial multi-antibody biosensing with TOPAS microstructured polymer optical fibers," Sensors (Switzerland), vol. 13, no. 3, pp. 3242-3251, 2013.

[10] N. Zhong et al., "A high-sensitivity fiber-optic evanescent wave sensor with a three-layer structure composed of Canada balsam doped with GeO2," Biosens. Bioelectron., vol. 85, pp. 876-882, 2016.

[11] J. B. Jensen, P. E. Hoiby, G. Emiliyanov, O. Bang, L. H. Pedersen, and A. Bjarklev, "Selective detection of antibodies in microstructured polymer optical fibers," Opt. Express, vol. 13, no. 15 , p. $5883,2005$.

[12] H. U. Hassan, J. Janting, S. Aasmul, and O. Bang, "Polymer Optical Fiber Compound Parabolic Concentrator fiber tip based glucose sensor: in-Vitro Testing," IEEE Sens. J., vol. 16, no. 23, pp. 8483$8488,2016$.

[13] N. Zhong, Q. Liao, X. Zhu, M. Zhao, Y. Huang, and R. Chen, "Temperature-independent polymer optical fiber evanescent wave sensor," Sci. Rep., vol. 5, pp. 1-10, 2015.

[14] G. Woyessa, K. Nielsen, A. Stefani, C. Markos, and O. Bang, "Temperature insensitive hysteresis free highly sensitive polymer optical fiber Bragg grating humidity sensor," Opt. Express, vol. 24, no. 2, p. 1206, 2016.

[15] C. Markos, A. Stefani, K. Nielsen, H. K. Rasmussen, W. Yuan, and O. Bang, "High-Tg TOPAS microstructured polymer optical fiber for fiber Bragg grating strain sensing at 110 degrees.," Opt. Express, vol. 21, no. 4, pp. 4758-65, 2013.

[16] G. Woyessa, A. Fasano, C. Markos, H. Rasmussen, and O. Bang, "Low loss polycarbonate polymer optical fiber for high temperature FBG humidity sensing," IEEE Photonics Technol. Lett., vol. 29, no. 7, pp. 1-1, 2017.

[17] C. A. F. Marques, D. J. Webb, and P. Andre, "Polymer optical fiber sensors in human life safety," Opt. Fiber Technol., vol. 36, pp. 144154, 2017.

[18] K. Kalli, A. Theodosiou, and A. Lacraz, "Femtosecond laser inscribed Bragg grating arrays in long lengths of polymer optical fibres; a route to practical sensing with POF," Electron. Lett., vol. 52, no. 19, pp. 1626-1627, 2016.

[19] Y. Luo et al., "Analysis of multimode POF gratings in stress and strain sensing applications," Opt. Fiber Technol., vol. 17, no. 3, pp. 201-209, 2011

[20] A. Lacraz, M. Polis, A. Theodosiou, C. Koutsides, and K. Kalli, "Femtosecond Laser Inscribed Bragg Gratings in Low Loss CYTOP Polymer Optical Fiber," IEEE Photonics Technol. Lett., vol. 27, no. 7, pp. 693-696, 2015.

[21] M. C. J. Large, L. Poladian, G. W. Barton, and M. A. van Eijkelenborg, Microstructured Polymer Optical Fibres. Springer, 2008.

[22] O. Ziemann, J. Krauser, P. E. Zamzow, and W. Daum, POF Handbook: Optical Short Range Transmission Systems. 2008.

[23] A. G. L. Junior, A. Frizera, and M. J. Pontes, "Analytical model for a polymer optical fiber under dynamic bending," Opt. Laser Technol., vol. 93, pp. 92-98, 2017.

[24] M. C. J. Large, J. Moran, and L. Ye, "The role of viscoelastic properties in strain testing using microstructured polymer optical fibres (mPOF)," Meas. Sci. Technol., vol. 20, no. 3, p. 34014, 2009.

[25] I.-L. Bundalo, K. Nielsen, G. Woyessa, and O. Bang, "Long-term strain response of polymer optical fiber FBG sensors," Opt. Mater. Express, vol. 7, no. 3, pp. 401-403, 2017.

[26] A. Stefani, S. Andresen, W. Yuan, and O. Bang, "Dynamic characterization of polymer optical fibers," IEEE Sens. J., vol. 12, no. 10, pp. 3047-3053, 2012

[27] W. Zhang and D. J. Webb, "Humidity responsivity of poly(methyl methacrylate)-based optical fiber Bragg grating sensors," Opt. Lett., vol. 39, no. 10, p. 3026, May 2014.

[28] A. G. Leal-Junior, C. Marques, A. Frizera, and M. J. Pontes, "Dynamic Mechanical Analysis on a PolyMethyl Methacrylate (PMMA) Polymer Optical Fiber," IEEE Sens. J., vol. 1748, no. c, pp. 1-1, 2018.

[29] A. Stefani, K. Nielsen, H. K. Rasmussen, and O. Bang, "Cleaving of TOPAS and PMMA microstructured polymer optical fibers: Coreshift and statistical quality optimization," Opt. Commun., vol. 285, no. 7, pp. 1825-1833, 2012.

[30] W. Yuan et al., "Improved thermal and strain performance of annealed polymer optical fiber Bragg gratings," Opt. Commun., vol. 284, no. 1, pp. 176-182, 2011.

[31] N. Zhong, M. Zhao, Q. Liao, X. Zhu, Y. Li, and Z. Xiong, "Effect of heat treatments on the performance of polymer optical fiber sensor," Opt. Express, vol. 24, no. 12, p. 13394, 2016. 